\title{
Pulmonary artery involvement in Takayasu's arteritis: diagnosis before pulmonary hypertension
}

\author{
Jing Yang ${ }^{1}$, Min Peng ${ }^{2^{*}}$, Juhong Shi ${ }^{2^{*}+}$, Wenjie Zheng ${ }^{3}$ and Xuezhong Yu ${ }^{1}$
}

\begin{abstract}
Background: This study was performed to analyze the clinical manifestations, imaging features, and prognosis of Takayasu's arteritis (TA) with pulmonary arteritis (PA).

Methods: In total, 51 of 815 patients with TA were diagnosed with PA at the Peking Union Medical College Hospital from 1986 to 2015. The patients' medical records and radiographic data were retrospectively reviewed.

Results: The patients comprised 39 women and 12 men with a median age of 33 years (range, 14-67 years). The most common symptoms were dyspnea (70.6\%), cough (66.7\%), hemoptysis (47.1\%), and chest pain (45.1\%). Computed tomography (CT) pulmonary angiography, pulmonary arteriography, and pulmonary perfusion imaging showed pulmonary artery stenosis or occlusion in 44 patients. A total of $82.4 \%$ of patients had lung parenchyma lesions on CT scans, indirectly indicating pulmonary artery involvement. Additionally, 58.8\% of patients had pulmonary hypertension $(\mathrm{PH})$ by echocardiography. Compared with the $\mathrm{PH}$ group, the non-PH group was characterized by a shorter disease duration; more symptoms such as fever, chest pain, and hemoptysis; an increased erythrocyte sedimentation rate; and a higher incidence of subpleural wedge-shaped shadows on chest $C T$ ( $P<$ 0.05). The median follow-up period was 48 months (range, 1-212 months), and all three deaths occurred in the PH group.

Conclusions: The clinical manifestations of TA with PA are nonspecific. PH often complicates PA and is associated with a poor prognosis. Early clinical manifestations such as repeated fever, chest pain, hemoptysis, and recurrence of subpleural wedge-shaped shadows on chest CT should arouse suspicion of PA in patients with TA and prompt further investigations. This may allow PA to be diagnosed before the occurrence of PH.
\end{abstract}

Trial registration: ClinicalTrials, NCT03189602. Date of registration: June 16, 2017. Retrospectively registered.

Keywords: Pulmonary arteritis, Pulmonary hypertension, Takayasu's arteritis, Chest CT scan

\section{Background}

Takayasu's arteritis (TA) is a form of chronic vasculitis primarily involving the large arteries and their main branches, and the pathological manifestation is arterial full-thickness inflammation [1]. TA can affect the aorta, subclavian artery, renal artery, iliac artery, coronary artery, and other blood vessels. The clinical manifestations

\footnotetext{
* Correspondence: pengmin@pumch.cn; ShiJH@pumch.cn

${ }^{+}$Min Peng and Juhong Shi contributed equally to this work.

${ }^{2}$ Department of Respiratory and Critical Care Medicine, Peking Union Medical College Hospital, Chinese Academy of Medical Sciences and Peking Union Medical College, No. 1 Shuaifuyuan, Dongcheng District, Beijing 100730, China

Full list of author information is available at the end of the article
}

vary greatly depending on the area, severity, and duration of vascular involvement. TA usually progresses through three stages [2]: an early stage characterized by nonspecific symptoms, a vasculitis stage characterized by a systemic inflammatory response and thickening of the vascular walls, and a static stage characterized by dissipating inflammation and occlusion of affected vessels. Notably, the vasculitis stage is a crucial period for diagnosis and treatment.

TA can involve the pulmonary artery $[3,4]$. The incidence of pulmonary arteritis (PA) in patients with TA varies greatly among studies $(0-56 \%)[5,6]$. Pulmonary hypertension $(\mathrm{PH})$ occurs in 12 to $13 \%$ of patients with

(c) The Author(s). 2019 Open Access This article is distributed under the terms of the Creative Commons Attribution 4.0 International License (http://creativecommons.org/licenses/by/4.0/), which permits unrestricted use, distribution, and 
TA and in $42.2 \%$ of patients with PA $[3,6,7]$. No largesample study of PA and $\mathrm{PH}$ in patients with TA has been performed to date. Only one Chinese hospital specializing in cardiovascular diseases reported that the incidence of $\mathrm{PH}$ in patients with TA involving the pulmonary artery reached $78.1 \%$ [8]. Pulmonary artery involvement in patients with TA increases the likelihood of misdiagnosis or delayed diagnosis because of the nonspecific respiratory manifestations and lack of symptoms of systemic vessel involvement [9]. PH is a late manifestation of PA that indicates a weaker response to treatment and a poor prognosis [3]; thus, it is vital to achieve an early diagnosis of PA in patients with TA.

This study was performed to analyze the clinical manifestations, imaging features, and prognosis of TA with PA, focusing on the difference between patients with and without PH. Additionally, the early manifestations of PA were explored so that diagnosis can be achieved as early as possible before the occurrence of $\mathrm{PH}$.

\section{Methods}

\section{Study population}

Patients with TA who were hospitalized at Peking Union Medical College Hospital (PUMCH) from January 1986 to December 2015 were identified from the medical records system. Patients with TA who fulfilled the criteria for pulmonary artery involvement were included.

\section{Inclusion criteria}

1. Satisfaction of the diagnostic criteria for TA as defined by the American College of Rheumatology [10].

2. Pulmonary artery involvement as determined by satisfaction of at least one of the following three items: (1) computed tomography pulmonary angiography (CTPA), pulmonary perfusion imaging, or pulmonary arteriography findings suggestive of thickening of the vessel wall or stenosis or occlusion of the pulmonary artery branches; (2) ${ }^{18} \mathrm{~F}$ fluorodeoxyglucose positron emission tomography/ computed tomography (PET/CT) findings suggestive of high intake of local radioactive material in the pulmonary artery wall; or (3) transthoracic echocardiography findings consistent with presumptive $\mathrm{PH}$ without left ventricular disease. $\mathrm{PH}$ was defined as an estimated pulmonary artery systolic pressure (PASP) of $>50 \mathrm{mmHg}$ and peak tricuspid regurgitation velocity (TRV) of $>3.4$ $\mathrm{m} / \mathrm{s}$, which suggests a high probability of $\mathrm{PH}$ according to the European Society of Cardiology/ European Respiratory Society PH guideline [11, 12]. Estimation of the PASP was based on the peak TRV, taking into account the right atrial pressure as described by the simplified Bernoulli equation. The right atrial pressure was estimated by echocardiography and was based on the diameter and respiratory variation in diameter of the inferior vena cava $[12,13]$.

\section{Characteristics}

All patients' case records and imaging findings were retrospectively reviewed. Observation indices included demographic information, clinical manifestations, radiologic findings, laboratory examination findings, diagnostic procedures, therapeutic interventions, and outcomes. Patients with TA with pulmonary artery involvement were further divided into a $\mathrm{PH}$ group and non- $\mathrm{PH}$ group for comparison. The prognostic information was collected by telephone follow-up.

\section{Statistical analysis}

Data were analyzed using SPSS 17.0 (SPSS Inc., Chicago, IL, USA) and are expressed as median (range). The measurement data were analyzed by analysis of variance or the Mann-Whitney $U$ test to compare within- or between-group differences. The enumeration data were analyzed by the $x^{2}$ test. Survival rate analysis was performed using Kaplan-Meier and Cox regression methods. A $P$ value of $<0.05$ was considered statistically significant.

\section{Results}

\section{General information}

From January 1986 to December 2015, a total of 815 patients with TA were hospitalized in PUMCH, among whom 51 (6.26\%) were found to have PA (Fig. 1). According to their date of diagnosis, the patients were divided into six groups at 5-year intervals. The number of patients with TA increased over time ( $n=37,58,54,143,209$, and 314). In addition, the proportion of patients with PA among those with TA also showed an upward trend with time (0.0, 0.0, 1.9, 2.1, 7.2, and 10.2\%) (Fig. 2).

The 51 patients comprised 39 females and 12 males at a male:female ratio of 1.0:3.2; the median age of the patients was 33 (14-67) years. Among the 51 patients with PA, 30 (58.8\%) were diagnosed with presumptive PH [median estimated PASP, 84.5 (52-139) mmHg; median peak TRV, $4.25(3.5-5.6) \mathrm{m} / \mathrm{s}$ ] by transthoracic echocardiography. This number of patients with $\mathrm{PH}$ accounted for $93 \%$ of those in the previous 5 years $(2006-2010)$ but for only $50 \%$ of those in the more recent 5 years (2011-2015). The median duration from onset to hospitalization was 28 (1-540) months. The median duration from disease onset to hospitalization was longer in the $\mathrm{PH}$ group [45.5 (1- 


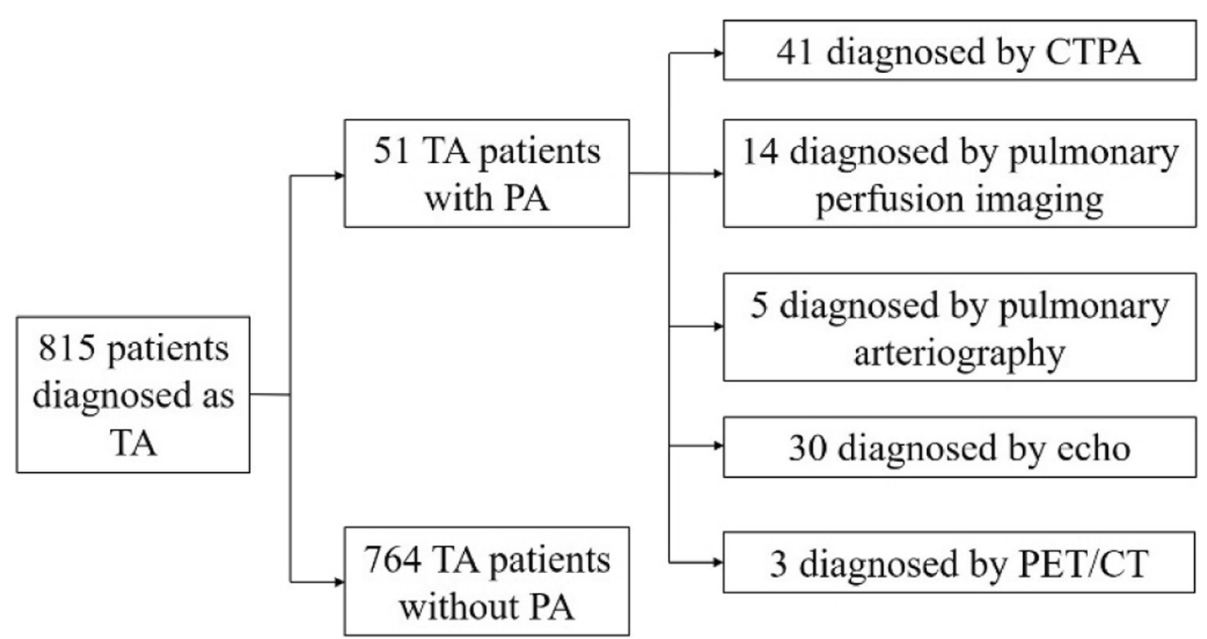

Fig. 1 Diagnostic flow chart of patients who had Takayasu's arteritis with pulmonary artery involvement

540) months] than in the non-PH group [17 (1-120) months, $P=0.009$ ] (Table 1 ).

\section{Clinical manifestations}

Respiratory symptoms occurred in 48 patients (94.1\%): dyspnea, $70.6 \% \quad(36 / 51)$; cough, $66.7 \% \quad(34 / 51)$; hemoptysis, $47.1 \%$ (24/51); and chest pain, $45.1 \%$ (23/ 51). Respiratory symptoms were the initial manifestation in 37 patients $(72.5 \%)$. Patients without $\mathrm{PH}$ were more likely to have symptoms such as fever $(61.9 \%$ vs. $30.0 \%$, $P=0.024)$, chest pain $(71.4 \%$ vs. $26.7 \%, P=0.002)$, or hemoptysis $(66.7 \%$ vs. $33.3 \%, P=0.019)$ but were less likely to feel dyspnea than patients with $\mathrm{PH}(52.4 \%$ vs. 83.3\%, $P=0.017$ ) (Table 1).
In terms of the distribution of involved vessels, 12 of 51 patients $(23.5 \%)$ only had PA and no evidence of extrapulmonary large artery involvement. Extrapulmonary vascular involvement occurred in 39 patients, including the aorta in 25 patients, carotid artery in 32, subclavian artery in 30 , renal artery in 18 , vertebral artery in 6 , mesenteric artery in 6 , iliac artery in 3 , and coronary artery in 2 .

\section{Laboratory examinations}

The leukocyte count in peripheral blood was 9.07 (4.06$18.46) \times 10^{9} / \mathrm{L}$, and the neutrophil count was $5.72(3.56-$ $16.29) \times 10^{9} / \mathrm{L}$. The erythrocyte sedimentation rate (ESR) was $16(1-178) \mathrm{mm} / \mathrm{h}$ and C-reactive protein level was $7.17(0.11-238.31) \mathrm{mg} / \mathrm{dL}$. The ESR was markedly higher

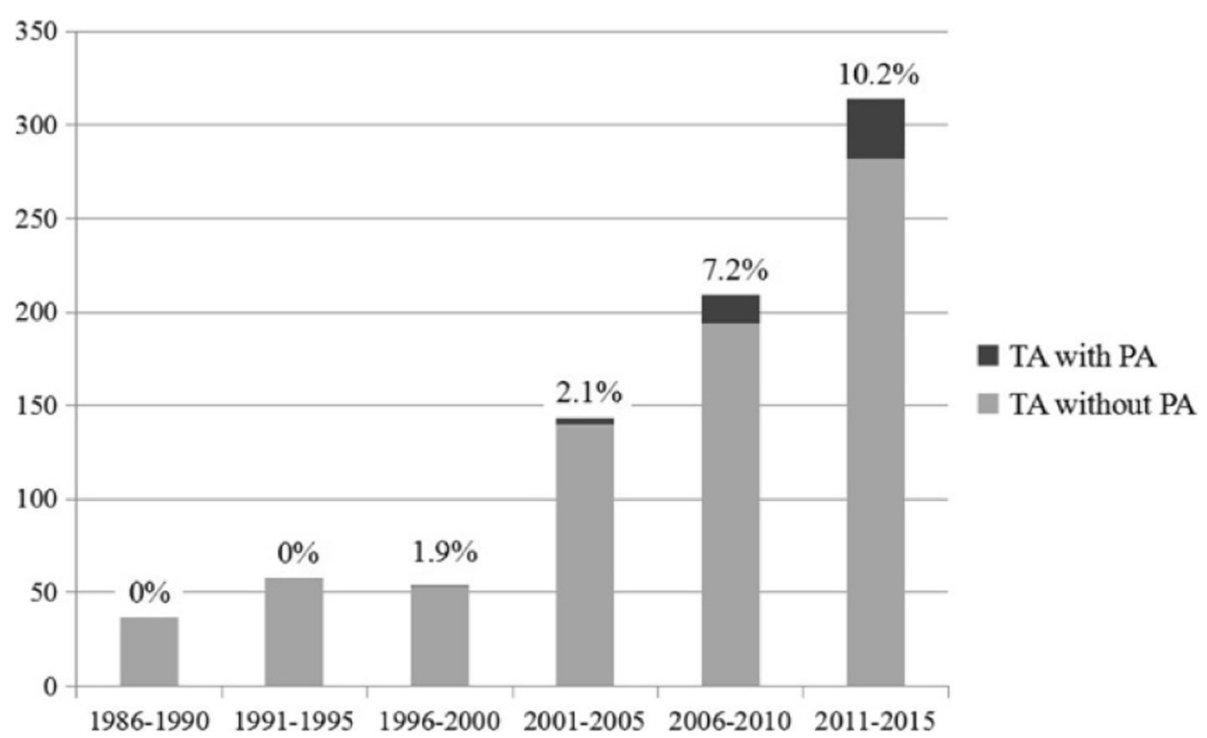

Fig. 2 Number of patients with Takayasu's arteritis (TA) and proportion of patients with pulmonary arteritis (PA) among those with TA gradually increased over 30 years 
Table 1 demographics, clinical manifestations, imaging features of Takayasu's arteritis patients with pulmonary arteritis

\begin{tabular}{|c|c|c|c|c|}
\hline & total $(n=51)$ & non-PH $(n=21)$ & $\mathrm{PH}(n=30)$ & $P$ \\
\hline Sex (female) & $39(76.5 \%)$ & $15(71.4 \%)$ & $24(80 \%)$ & 0.518 \\
\hline Age (year) & $33(14-67)$ & $30(15-65)$ & $35.5(22-67)$ & 0.196 \\
\hline Median duration of disease (months) & $28(1-540)$ & $17(1-120)$ & $45.5(1-540)$ & $0.009^{*}$ \\
\hline \multicolumn{5}{|l|}{ Clinical symptoms } \\
\hline Cough & $34(66.7 \%)$ & $15(71.4 \%)$ & $19(63.3 \%)$ & 0.546 \\
\hline Hemoptysis & $24(47.1 \%)$ & 14 (66.7\%) & 10 (33.3\%) & $0.019^{*}$ \\
\hline Dyspnea & $36(70.6 \%)$ & $11(52.4 \%)$ & $25(83.3 \%)$ & $0.017^{*}$ \\
\hline Chest pain & $23(45.1 \%)$ & $15(71.4 \%)$ & $8(26.7 \%)$ & $0.002^{*}$ \\
\hline Palpitation & $12(23.5 \%)$ & $4(19.0 \%)$ & $8(26.7 \%)$ & 0.767 \\
\hline Fever & $22(43.1 \%)$ & $13(61.9 \%)$ & $9(30.0 \%)$ & $0.024^{*}$ \\
\hline \multicolumn{5}{|l|}{ Lab tests } \\
\hline WBC $\left(\times 10^{9} / \mathrm{L}\right)$ & $9.07(4.06-18.46)$ & $9.80(8.92-17.00)$ & $8.48(4.06-18.46)$ & 0.246 \\
\hline $\mathrm{ESR}(\mathrm{mm} / \mathrm{h})$ & $16(1-178)$ & $34(2-178)$ & $8.5(1-140)$ & $0.027^{*}$ \\
\hline $\mathrm{CRP}(\mathrm{mg} / \mathrm{dL})$ & $7.17(0.11-238.31)$ & $13.7(0.37-238.31)$ & $5.65(0.11-155.00)$ & 0.284 \\
\hline \multicolumn{5}{|l|}{ Radiological features } \\
\hline Cavity & $7(13.7 \%)$ & $5(23.8 \%)$ & $2(6.7 \%)$ & 0.181 \\
\hline Nodule & $25(49.0 \%)$ & $11(52.4 \%)$ & $14(46.7 \%)$ & 0.688 \\
\hline Pleural thickening & $27(52.9 \%)$ & $10(47.6 \%)$ & $17(56.7 \%)$ & 0.524 \\
\hline irregular linear opacities & $26(51.0 \%)$ & $11(52.4 \%)$ & $15(50.0 \%)$ & 0.867 \\
\hline Patchy opacities & $27(52.9 \%)$ & $12(57.1 \%)$ & $15(50.0 \%)$ & 0.615 \\
\hline Subpleural wedge-shaped shadow & $13(25.5 \%)$ & $10(42.9 \%)$ & $3(10.0 \%)$ & $0.002^{*}$ \\
\hline Mosaic perfusion & $3(5.9 \%)$ & 0 & $3(10.0 \%)$ & 0.259 \\
\hline Extrapulmonary vascular involvement & $39(76.5 \%)$ & $13(61.9 \%)$ & $26(86.7 \%)$ & $0.040^{*}$ \\
\hline Aorta & $25(49.0 \%)$ & $8(38.1 \%)$ & $17(56.7 \%)$ & 0.192 \\
\hline Carotid artery & $32(62.7 \%)$ & $10(47.6 \%)$ & $22(73.3 \%)$ & 0.062 \\
\hline Vertebral artery & $6(11.8 \%)$ & $3(14.3 \%)$ & $3(10.0 \%)$ & 0.979 \\
\hline Subclavian artery & $30(58.8 \%)$ & $10(47.6 \%)$ & $20(66.7 \%)$ & 0.174 \\
\hline Mesenteric artery & $6(11.8 \%)$ & 0 & $6(20.0 \%)$ & $0.036^{*}$ \\
\hline Renal artery & $18(35.3 \%)$ & $4(19.0 \%)$ & $14(46.7 \%)$ & 0.083 \\
\hline Iliac artery & $3(5.9 \%)$ & $1(4.8 \%)$ & $2(6.7 \%)$ & 1.000 \\
\hline Coronary artery & $2(3.9 \%)$ & $1(4.8 \%)$ & $1(3.3 \%)$ & 1.000 \\
\hline
\end{tabular}

Values in parentheses indicate percentage or range. CRP C-reactive protein, ESR Erythrocyte sedimentation rate, $W B C$ White blood cells. ${ }^{*} P<0.05$

in the patients without than with $\mathrm{PH}(34$ vs. $8.5 \mathrm{~mm} / \mathrm{h}$, $P=0.027)$ (Table 1).

\section{Imaging findings}

Chest CT showed pulmonary parenchymal involvement in 42 of 51 (82.4\%) patients with TA involving the pulmonary artery: pleural thickening in 27 patients (52.9\%), patchy opacities in 27 (52.9\%), irregular linear opacities in 26 (51.0\%) (Fig. 3b, e and Fig. 4e), nodules in 25 (49.0\%) (Fig. 3a), subpleural wedge-shaped shadows in 13 (25.5\%) (Fig. 3c and Fig. 4a to c), cavities in 7 (13.7\%) (Fig. 3a), and mosaic perfusion in 3 (5.9\%) (Fig. 3a). The proportion of subpleural wedge-shaped shadows was significantly higher in the non- $\mathrm{PH}$ group than $\mathrm{PH}$ group $\left(x^{2}=9.204, P=0.002\right)($ Table 1$)$.
Of the 44 patients who underwent pulmonary vascular imaging, 41 underwent CTPA showing pulmonary artery stenosis in 33 patients (Fig. 3f and Fig. 4d), pulmonary artery occlusion in 32 (Fig. 3d, f and Fig. 4f), pulmonary artery wall thickening in 14, and pulmonary artery expansion in 7. Five patients underwent pulmonary arteriography, which showed pulmonary artery stenosis and occlusion. Pulmonary perfusion imaging in 14 patient revealed perfusion defects.

\section{Diagnosis and differential diagnosis}

Forty-four patients with PA were diagnosed by pulmonary vascular imaging examinations (CTPA in 41, pulmonary perfusion imaging in 14 , and pulmonary arteriography in 5; at least two pulmonary vascular imaging abnormalities were found in 14 patients). Three 


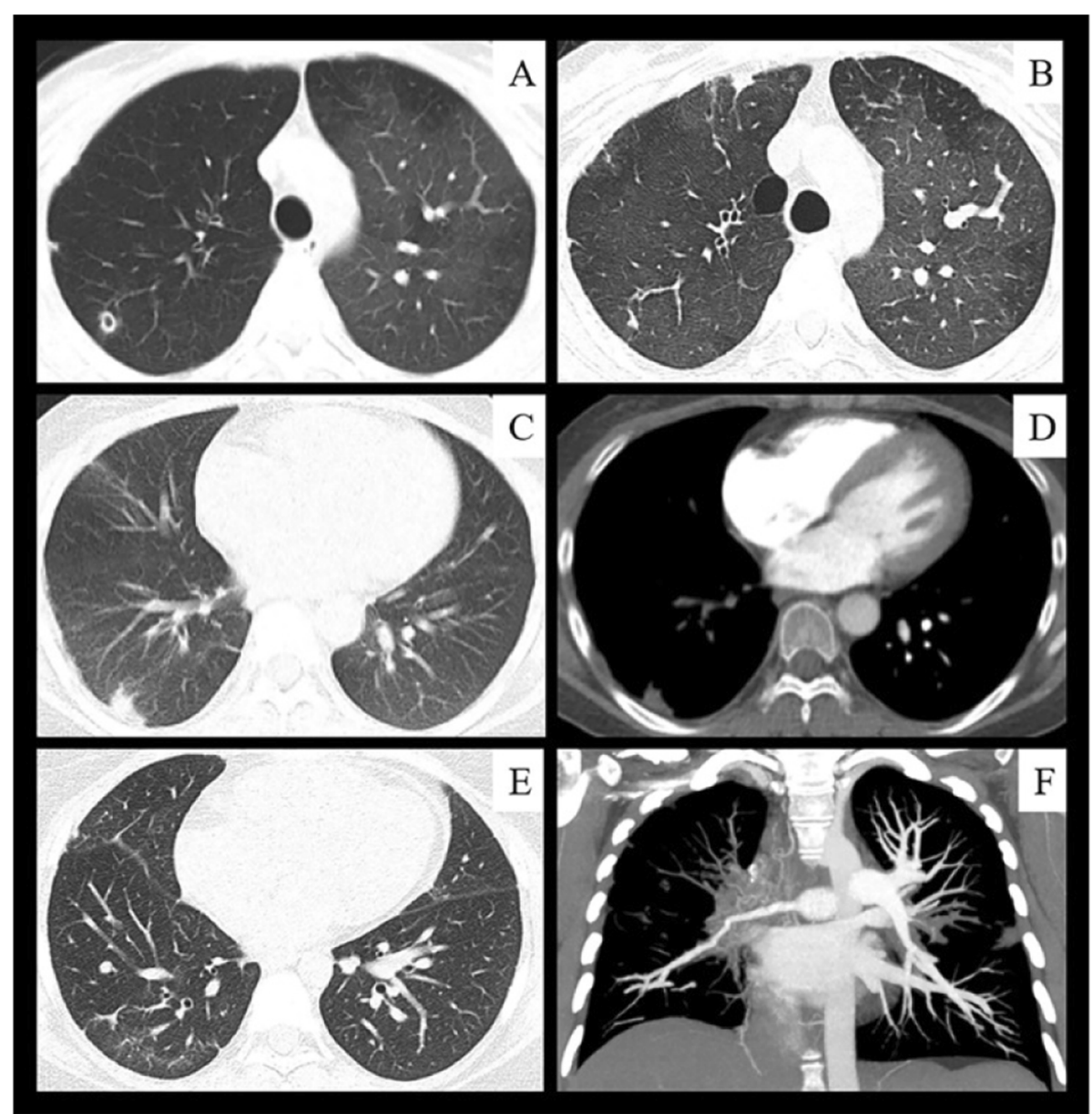

Fig. 3 Imaging findings of pulmonary arteritis in patients with Takayasu's arteritis. a, Axial computed tomography (CT) image shows mosaic perfusion with reduced vessels in the darker lung (right lung), indicating occlusive vascular disease; a thin wall cavity is present in the right upper lung, consistent with pulmonary infarction. $\mathbf{b}$, CT image obtained 2 years later shows a healing residual lesion from the cavity of the right upper lobe; subpleural scarring is also present. c, CT image shows a subpleural wedge-shaped opacity suggestive of pulmonary infarction. $\mathbf{d}$, Contrastenhanced CT image shows corresponding pulmonary artery occlusion in the right lower lobe. e, CT image shows peripheral scarring from previous infarcts in the right lower lung. $\mathbf{f}$, Coronal reformatted image from $\mathrm{CT}$ pulmonary angiography in the same patient as in (e) shows occlusion of the right upper lobe artery and stenosis of the right interlobar artery and lower lobe artery

patients underwent systemic PET/CT scans showing pulmonary artery involvement. Six patients were diagnosed only by echocardiography (Fig. 1).

Forty-two (82.4\%) patients had been diagnosed with other diseases before the diagnosis of PA, including pulmonary infection in 21 (50.0\%), pulmonary tuberculosis in 13 (31.0\%), idiopathic $\mathrm{PH}$ in 9 (21.4\%), pulmonary embolism in 5 (11.9\%), bronchial dilatation in 4 (9.5\%), myocarditis in $2(4.8 \%)$, heart failure in $2(4.8 \%)$, lung malignancies in $1(2.4 \%)$, and allergic pneumonia in 1 (2.4\%).

\section{Treatment and prognosis}

Fifty-one patients were treated with a glucocorticoid at a starting dose of 0.5 to $1.0 \mathrm{mg} / \mathrm{kg} /$ day; 45 patients received immunosuppressive therapy (39 with cyclophosphamide, 4 with methotrexate, 3 with azathioprine, 1 with tacrolimus, 1 with cyclosporine A, 1 with mycophenolate mofetil, and 1 with triptolide; 3 patients received treatment with two or more disease-modifying antirheumatic drugs). Seventeen patients received aspirin antiplatelet therapy, 17 were treated with warfarin anticoagulation, and 5 were treated with both aspirin and warfarin.

Fifty-one patients with TA involving the pulmonary artery were followed up for 48(1-212) months. Three of these patients died, and all were in the $\mathrm{PH}$ group. Eleven patients were readmitted to the hospital because of TArelated clinical manifestations, including nine patients in the $\mathrm{PH}$ group and two in the non- $\mathrm{PH}$ group. Patients without $\mathrm{PH}$ had significantly lower mortality and readmission rates than those with $\mathrm{PH}(9.5 \%$ vs. 33.3\%). 


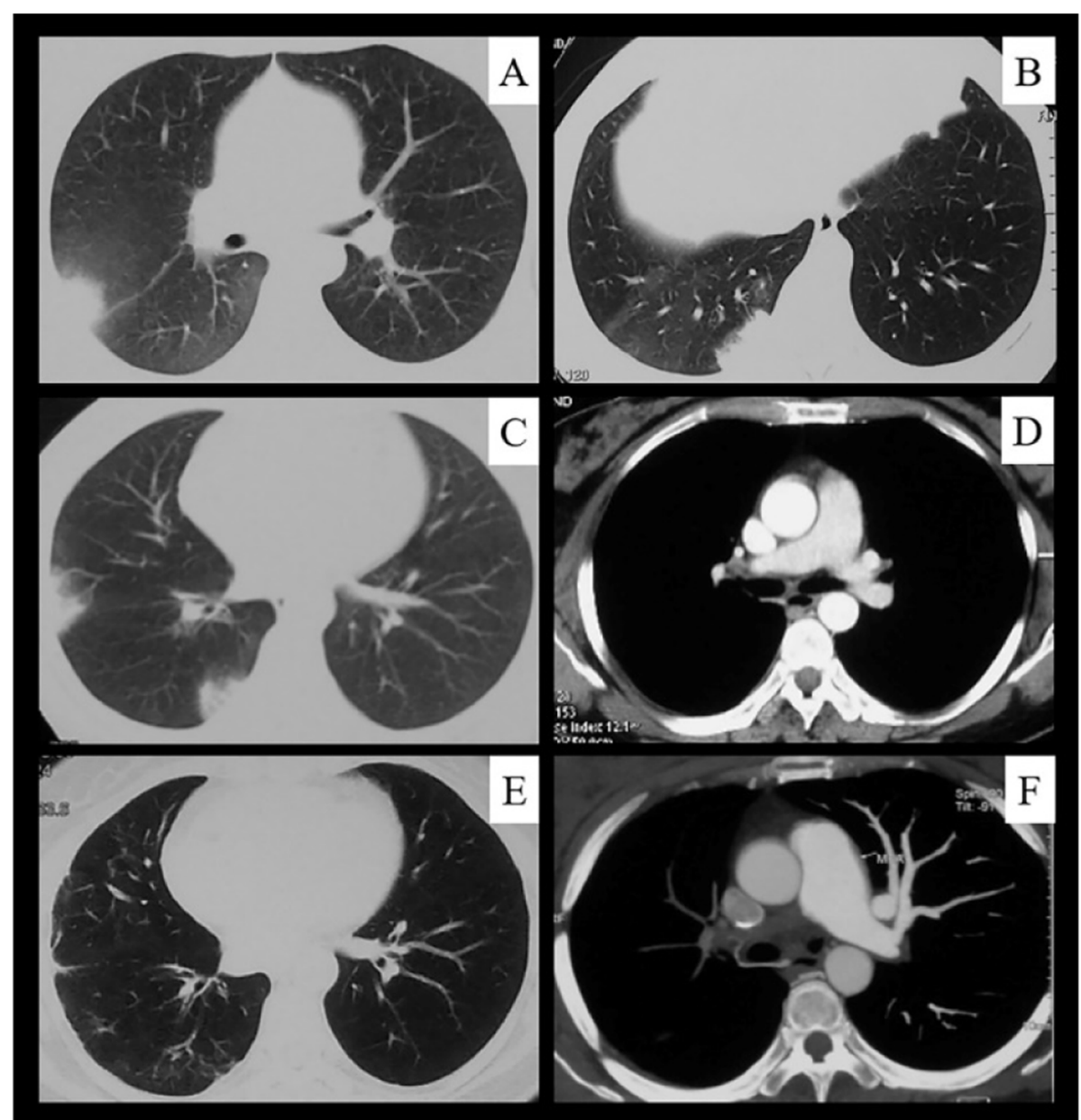

Fig. 4 Serial computed tomography (CT) images in a 40-year-old woman with Takayasu's arteritis. The patient was admitted to our hospital because of shortness of breath. She had developed recurrent chest and back pain and hemoptysis 4 years previously. a-c, CT images show recurrent subpleural wedge-shaped opacities during the initial 6 months after disease onset. $\mathbf{d}$ CT pulmonary angiography (CTPA) image obtained at the same time as in (c) showed right pulmonary artery stenosis. e, four years later, a CT image shows peripheral scarring from previous infarcts. f, CTPA image obtained at the same time showed right pulmonary artery occlusion

The Kaplan-Meier survival analysis showed that the risk of death or repeated hospital admissions significantly decreased if the PASP was $<100 \mathrm{mmHg}$ (Fig. 5). Cox regression analysis showed that the risk of death or readmission significantly increased if the PASP was $\geq 100 \mathrm{mmHg}$ in patients with PA after adjusting for the patients' demographics (age and sex), PASP, ESR, CRP, and presence or absence of extrapulmonary involvement [hazard ratio (HR), 18.00; 95\% confidence interval, 3.5192.29; $P=0.001]$. An ESR of $\geq 20 \mathrm{~mm} / \mathrm{h}$ was the key factor for reducing the risk of death or repeated hospital admissions (HR, 0.15; 95\% confidence interval, 0.03$0.78 ; P=0.024)$.

\section{Discussion}

In the present study, we reviewed 815 patients with TA during a 30 -year period in a single center and found that
(1) PA was present in $6.3 \%$ of patients with TA and that this proportion increased over time, (2) 58.8\% (30/51) of patients with PA developed PH, and (3) 82.4\% (42/51) of patients with PA had lung parenchymal lesions on CT scans, representing indirect signs of pulmonary artery involvement. Compared with the $\mathrm{PH}$ group, the non- $\mathrm{PH}$ group had different clinical features and imaging findings and a better prognosis.

The proportion of PA among patients with TA is still unclear and varies greatly among previous studies, which may be related to differences between study populations or diagnostic methods $[5,6,14-18]$. In the present study, we found that PA occurred in $6.3 \%$ of patients with TA. Notably, the rate of PA in patients with TA continually increased over time and reached $10 \%$ of patients with TA. The increasing diagnosis rate was due to the increasing awareness of TA and pulmonary vasculitis 


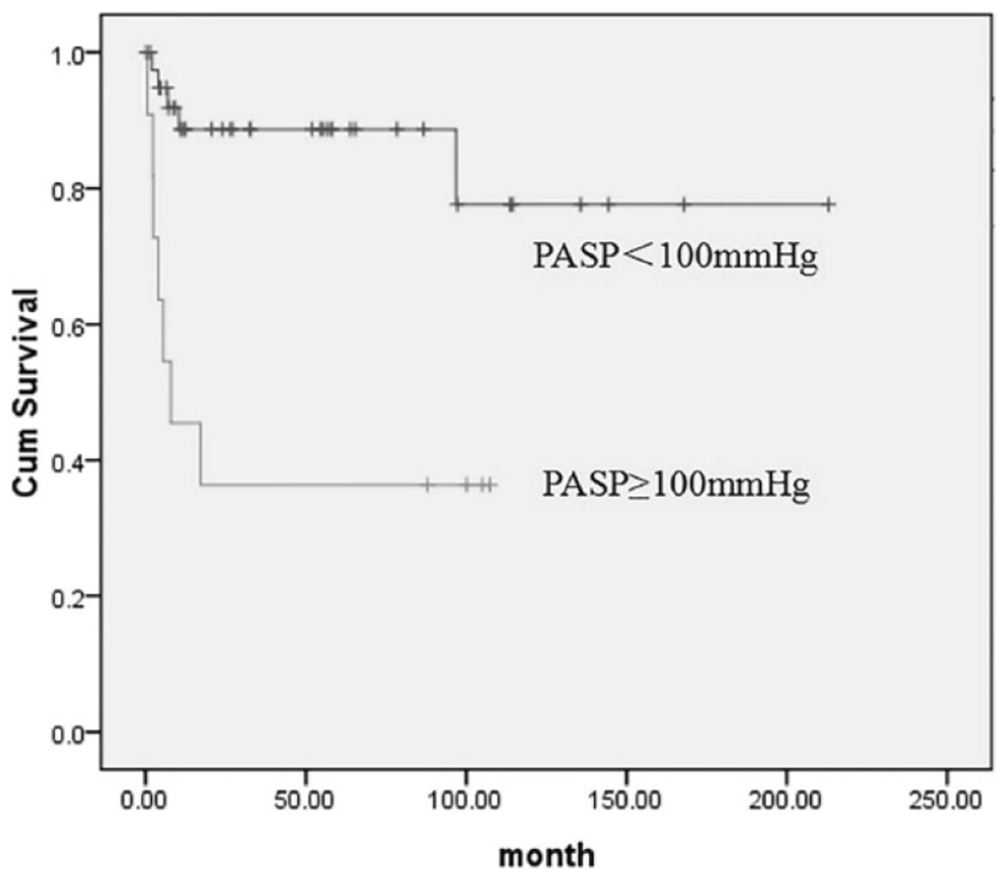

Fig. 5 Kaplan-Meier analysis of the risk of death or repeated hospital admissions. Patients with a PASP of $\geq 100 \mathrm{mmHg}$ had a greater risk of death or repeated hospital admissions than patients with a PASP of $<100 \mathrm{mmHg}$

among clinicians in our center; it was also associated with improvements in diagnostic methods. For example, CTPA and PET/CT have become more widely used during the past 10 years in our clinic. This result also suggests that a previously considerable number of patients who had TA with PA were probably underdiagnosed, implying that more attention should be paid to screening these patients in future.

The symptoms of PA are insidious and nonspecific. The main symptoms in this study were dyspnea (70.6\%), cough (66.7\%), hemoptysis (47.1\%), and chest pain (45.1\%), while $5.9 \%$ of patients had no respiratory symptoms. This finding is consistent with a meta-analysis by Toledano et al [3]. Patients who have TA with pulmonary artery involvement have occult-onset and nonspecific symptoms, making early diagnosis difficult. Previous studies have shown that the delays in diagnosis and treatment range from 3 to 72 months in patients with PA $[9,19,20]$. In the present study, the median time from the initial symptoms to definitive diagnosis was 13.5 (1-186) months. In addition, $80 \%$ of patients in this study were diagnosed with other diseases at their first visit, mostly pulmonary infection, pulmonary tuberculosis, idiopathic $\mathrm{PH}$, and pulmonary embolism, consistent with previous studies $[9,20,21]$. Thus, identification of PA in patients with TA is challenging for physicians.

Accurate diagnosis of pulmonary artery involvement virtually always depends on imaging studies because the clinical manifestations and laboratory test results are usually nonspecific. Typical CT manifestations of pulmonary artery involvement include artery wall thickening and enhancement in the early disease stages and luminal stenosis or occlusion in the chronic stages [22, 23]. Few previous studies or monographs have mentioned changes in the lung parenchyma [22-24]. Occasional case reports have shown that pulmonary infarction is a rare clinical manifestation in patients with TA $[25,26]$ and that chest CT commonly shows a subpleural wedge-shaped shadow [27, 28]. Unlike the results of previous studies, our results showed that up to $82.4 \%$ of patients who had TA with PA showed lung parenchymal changes on chest $\mathrm{CT}$, which might have been secondary to pulmonary vasculitis. The subpleural wedgeshaped shadow was probably the pulmonary infarction caused by PA inflammation-induced vascular stenosis, occlusion, or in situ thrombosis. Pulmonary cavities were probably due to pulmonary parenchymal ischemia and necrosis. Mosaic perfusion indicated vascular occlusion and reduced blood flow. Peripheral irregular linear opacities indicated prior lung infarction. Our results showed that in addition to direct signs such as pulmonary artery wall thickening or narrowing, the imaging findings of pulmonary vasculitis also have indirect signs; i.e., changes in the lung parenchyma that indicate pulmonary artery involvement and should prompt further pulmonary vascular investigations such as CTPA.

TA-related PH is classified as group $4 \mathrm{PH}$ (i.e., chronic thromboembolic $\mathrm{PH}$ and other pulmonary obstruction) 
[12]. The present study showed that $\mathrm{PH}$ occurred in $58.8 \%$ of patients with PA, consistent with previous studies $(42.2-78.1 \%)[3,8]$. All three deaths in this study were related to severe $\mathrm{PH}$, suggesting that $\mathrm{PH}$ might be related to a poor prognosis and increased mortality. Therefore, early diagnosis is particularly important. Notably, the rate of $\mathrm{PH}$ decreased during the most recent 5 years (2011-2015) compared with the previous 5 years (2006-2010) in our center $(50.0 \%$ vs. $94.3 \%$, respectively). This result prompts us to consider the possibility of further reducing the incidence of $\mathrm{PH}$ in patients with TA with pulmonary artery involvement in the future. The present study showed that the clinical and imaging findings differed between the $\mathrm{PH}$ and non-PH group. Compared with the $\mathrm{PH}$ group, the non- $\mathrm{PH}$ group was characterized by a shorter disease course; more symptoms such as fever, chest pain, and hemoptysis; an increased ESR; and a higher incidence of subpleural wedge-shaped shadows on chest $\mathrm{CT}$, suggesting that patients in the non-PH group were in the early and active inflammatory stage. Therefore, the early manifestations of PA include recurrent fever, chest pain, hemoptysis, an elevated ESR, and recurrent subpleural wedge-shaped shadows, which should raise suspicious for PA and prompt further vascular imaging investigations. This may allow TA to be diagnosed before the occurrence of $\mathrm{PH}$.

Our study has several limitations. It was retrospective in nature, not all patients routinely received pulmonary vascular-related examinations, and the diagnostic approaches were inconsistent. Right ventricular catheterization, which is the gold standard for the diagnosis of $\mathrm{PH}$, was not performed. Thus, the exact incidence of $\mathrm{PH}$ in patients with TA is unknown and should be confirmed in future studies. Additionally, we only included hospitalized patients with TA, whose condition was more severe than that of outpatients, possibly leading to selection bias. Therefore, a multicenter prospective cohort study will be required to confirm our results.

\section{Conclusions}

The clinical manifestations of TA involving the pulmonary artery are nonspecific, making this condition subject to misdiagnosis and delayed diagnosis. $\mathrm{PH}$ often complicates PA and is associated with a poor prognosis. Early clinical manifestations such as repeated fever, chest pain, hemoptysis with or without dyspnea, and recurrence of subpleural wedge-shaped shadows on chest CT should arouse suspicion for PA in patients with TA and prompt further vascular imaging investigations. This may allow TA to be diagnosed early, before the occurrence of irreversible stenotic and fibrotic vascular lesions.

\section{Abbreviations}

CRP: C-reactive protein; CTPA: Computed tomography pulmonary angiography; ESR: Erythrocyte sedimentation rate; PA: Pulmonary arteritis; PASP: Pulmonary arterial systolic pressure; PET/CT: Positron emission tomography/computed tomography; PH: Pulmonary hypertension; PUMCH: Peking Union Medical College Hospital; TA: Takayasu's arteritis; TRV: Tricuspid regurgitation velocity; WBC: White blood cells; HR: Hazard ratio

\section{Acknowledgements}

Not applicable.

\section{Authors' contributions}

JY and MP collected the data and images. JS, MP and JY analyzed the information of pulmonary artery involved TA patients. JY was a major contributor in writing the manuscript. JS, MP, WZ and XY reviewed the manuscript. All authors read and approved the final manuscript. MP and JS made equal contribution to this study.

\section{Funding}

This study was supported by the Ministry of Science and Technology of China "Precision medicine project" [grant number 2016YFC0905603]. This funding was used for data collection and manuscript writing.

\section{Availability of data and materials}

The datasets generated and analysed during the current study are available in the Clinica/Trials repository [https://clinicaltrials.gov/ct2/results?recrs= \&cond $=\&$ term $=$ NCT03189602\&cntry $=\&$ state $=\&$ city $=\&$ dist $=]$.

\section{Ethics approval and consent to participate}

All patients in this study were informed at admission that their medical records were likely to be used for clinical studies, and written informed consent was provided by the patient or his or her family. This study was approved by the Peking Union Medical College Ethics Review Committee (ethics number: s-634).

\section{Consent for publication}

Information (including data and images) were obtained from patients (or their legal guardian) with consent.

Competing interests

The authors declare that they have no competing interests.

\section{Author details}

${ }^{1}$ Department of Emergency, Peking Union Medical College Hospital, Chinese Academy of Medical Sciences and Peking Union Medical College, No. 1 Shuaifuyuan, Dongcheng District, Beijing 100730, China. ${ }^{2}$ Department of Respiratory and Critical Care Medicine, Peking Union Medical College Hospital, Chinese Academy of Medical Sciences and Peking Union Medical College, No. 1 Shuaifuyuan, Dongcheng District, Beijing 100730, China. ${ }^{3}$ Department of Rheumatology, Peking Union Medical College Hospital, Chinese Academy of Medical Sciences and Peking Union Medical College, No. 1 Shuaifuyuan, Dongcheng District, Beijing 100730, China.

Received: 11 December 2018 Accepted: 1 November 2019 Published online: 27 November 2019

References

1. Numano F, Okawara M, Inomata H, Kobayashi Y. Takayasu's arteritis. Lancet. 2000;356(9234):1023-5.

2. Castaner E, Alguersuari A, Gallardo X, Andreu M, Pallardo Y, Mata JM, et al. When to suspect pulmonary vasculitis: radiologic and clinical clues. Radiographics. 2010;30(1):33-53.

3. Toledano K, Guralnik L, Lorber A, Ofer A, Yigla M, Rozin A, et al. Pulmonary arteries involvement in Takayasu's arteritis: two cases and literature review. Semin Arthritis Rheum. 2011;41(3):461-70.

4. Wang X, Dang A, Chen B, Lv N, Liu Q. Takayasu arteritis-associated pulmonary hypertension. J Rheumatol. 2015;42(3):495-503.

5. Hotchi M. Pathological studies on Takayasu arteritis. Heart Vessels Suppl. 1992; $7: 11-7$

6. Sharma BK, Jain S, Radotra BD. An autopsy study of Takayasu arteritis in India. Int J Cardiol. 1998;66:S85-90. 
7. Bicakcigil M, Aksu K, Kamali S, Ozbalkan Z, Ates A, Karadag O, et al. Takayasu's arteritis in Turkey - clinical and angiographic features of 248 patients. Clin Exp Rheumatol. 2009;27(1 Suppl 52):S59-64.

8. Changming $X$, Zhihong $L$, Jianguo $H$. Xinhai $N$, xiansheng C. clinical analysis of pulmonary Vasculitis in 41 patients. Chin Circ J. 2010;25(1):44-6.

9. Karadag B, Kilic H, Duman D, Ongen Z, Vural VA, Yazici H. Takayasu disease with prominent pulmonary artery involvement: confusion with pulmonary disease leading to delayed diagnosis. Mod Rheumatol. 2008;18(5):507-10.

10. Arend WP, Michel BA, Bloch DA, Hunder GG, Calabrese LH, Edworthy SM, et al. The American College of Rheumatology 1990 criteria for the classification of Takayasu arteritis. Arthritis Rheum. 1990:33(8):1129-34.

11. Galie N, Hoeper MM, Humbert M, Torbicki A, Vachiery JL, Barbera JA, et al. Guidelines for the diagnosis and treatment of pulmonary hypertension: the task force for the diagnosis and treatment of pulmonary hypertension of the European Society of Cardiology (ESC) and the European Respiratory Society (ERS), endorsed by the International Society of Heart and Lung Transplantation (ISHLT). Eur Heart J. 2009;30(20):2493-537.

12. Galiè N, Humbert M, Vachiery JL, Gibbs S, Lang I, Torbicki A, et al. 2015 ESC/ ERS guidelines for the diagnosis and treatment of pulmonary hypertension: the joint task force for the diagnosis and treatment of pulmonary hypertension of the European Society of Cardiology (ESC) and the European Respiratory Society (ERS): endorsed by: Association for European Paediatric and Congenital Cardiology (AEPC), International Society for Heart and Lung Transplantation (ISHLT). Eur Respir J. 2015;46(4):903-75.

13. Simonneau G, Montani D, Celermajer DS, Denton CP, Gatzoulis MA, Krowka $M$, et al. Haemodynamic definitions and updated clinical classification of pulmonary hypertension. Eur Respir J. 2019;53(1):1801913.

14. Kerr GS, Hallahan CW, Giordano J, Leavitt RY, Fauci AS, Rottem M, et al. Takayasu arteritis. Ann Intern Med. 1994;120(11):919-29.

15. Arnaud L, Haroche J, Malek Z, Archambaud F, Gambotti L, Grimon G, et al. Is F-18Fluorodeoxyglucose positron emission tomography scanning a reliable way to assess disease activity in Takayasu arteritis? Arthritis Rheum. 2009;60(4):1193-200.

16. Hoffman GS, Merkel PA, Brasington RD, Lenschow DJ, Liang P. Anti-tumor necrosis factor therapy in patients with difficult to treat Takayasu arteritis. Arthritis Rheum. 2004:50(7):2296-304.

17. Kobayashi Y, Ishii K, Oda K, Nariai T, Tanaka Y, Ishiwata K, et al. Aortic wall inflammation due to Takayasu arteritis imaged with F-18-FDG PET coregistered with enhanced CT. J Nucl Med. 2005;46(6):917-22.

18. Lupi E, Sanchez G, Horwitz S, Gutierrez E. Pulmonary artery involvement in Takayasu's arteritis. Chest. 1975;67(1):69-74.

19. Jin SA, Lee JH, Park JH, Oh JK, Kim MS, Park YK, et al. Endovascular treatment in a patient with left Main coronary and pulmonary arterial stenosis as an initial manifestation of Takayasu's arteritis. Heart Lung Circ 2015;24(2):E26-30.

20. Hayashi K, Nagasaki M, Matsunaga N, Hombo Z, Imamura T. Initial pulmonary artery involvement in Takayasu arteritis. Radiology. 1986;159(2):401-3.

21. Brugiere O, Mal H, Sleiman C, Groussard O, Mellot F, Fournier M. Isolated pulmonary arteries involvement in a patient with Takayasu's arteritis. Eur Respir J. 1998;11(3):767-70.

22. Park JH, Chung JW, Im JG, Kim SK, Park YB, Han MC. Takayasu arteritis: evaluation of mural changes in the aorta and pulmonary artery with CT angiography. Radiology. 1995;196(1):89-93.

23. Castaner E, Alguersuari A, Andreu M, Gallardo X, Spinu C, Mata JM. Imaging findings in pulmonary vasculitis. Semin Ultrasound CT MR. 2012;33(6):567-79.

24. Müller NL. Imaging of the Chest. Saunders Elsevier; 2008. p. 845-50.

25. Elsasser S, Soler M, Bolliger C, Jager K, Steiger U, Perruchoud AP. Takayasu disease with predominant pulmonary involvement. Respiration. 2000;67(2):213-5.

26. Narita J, Ito S, Terada M, Saitoh Y, Igarashi K, Nakano M, et al. Pulmonary artery involvement in Takayasu's arteritis with lung infarction and pulmonary aspergillosis. J Clin Rheumatol. 2002;8(5):260-4.

27. Devouassoux G, Pison C, Witmeyer P, Tony F, Coulomb M, Brambilla C. Pulmonary infarction revealing pulmonary Takayasu's arteritis. Respir Med. 1998:92(7):969-7.

28. Nakamura T, Hayashi S, Fukuoka M, Sueoka N, Nagasawa K. Pulmonary infarction as the initial manifestation of Takayasu's arteritis. Intern Med. 2006:45(11):725-8

\section{Publisher's Note}

Springer Nature remains neutral with regard to jurisdictional claims in published maps and institutional affiliations.

Ready to submit your research? Choose BMC and benefit from:

- fast, convenient online submission

- thorough peer review by experienced researchers in your field

- rapid publication on acceptance

- support for research data, including large and complex data types

- gold Open Access which fosters wider collaboration and increased citations

- maximum visibility for your research: over $100 \mathrm{M}$ website views per year

At BMC, research is always in progress.

Learn more biomedcentral.com/submissions 